\title{
MANAGEMENT ISSUES
}

\section{The management series}

The articles in the management series deal with common management issues faced by A\&E consultants. The authors are practising A\&E consultants and a media specialist who have provided their way of addressing these issues. It is hoped that this series will contribute to the discussion of common management problems which we all face and need to be better prepared for.

Published in the November issue:

- Negotiating skills G Hughes

- Committees-a personal view G Hughes

To come:

- Giving critical feedback $M \mathcal{F}$ Clancy

- Chairing a meeting $C$ Cutting

- Dealing with the media VO'Loughlin

- How to find an SHO $H$ Guly

- How to appoint a senior house officer $H$ Guly

- How to conduct an SHO appraisal $M \mathcal{F}$ Clancy

- Organising training for undergraduates and SHOs

$N$ Rawlinson

- How to organise a higher training programme in A\&E H Guly

- Budget management $G$ Hughes

- Managing a bed crisis $N$ Egan

- Time management $C M c L a u c h l a n$

- Planning a rota I C Grant

- Complaints-and how to deal with them G Bryce

- Risk management $H R$ Guly

- Purchasing new equipment $C D H$ Oakland

- Organising a medical conference $\mathcal{f}$ Wyatt

- Disciplinary procedures I P Stewart

\section{Managing the managers}

The title of this article is explicit and might be considered condescending to health service managers. On the other hand, I am sure that managers also talk about managing doctors. I have no special qualifications to write on this subject and my thoughts are based upon personal experience during 20 years as a medical practitioner, nine of them in two different consultant posts. In theory I should therefore have encountered twice as many local managers as would otherwise have been the case. However, many colleagues have similar experiences. My personal approach to this subject is outlined below.

\section{Understanding managers}

It is always best to try and define a problem before tackling it. In the context of managing managers, I therefore consider it essential in the first instance to try and understand them. Managers are political individuals who need to satisfy their superiors, be they senior managers, health purchasers, or full time politicians at local or national level. They are expected to take a position on all matters and this is a challenge, as they may have little experience of the subject under discussion and may be poorly briefed on several aspects, including clinical priorities. For this reason it is important that managers are appraised of pertinent clinical problems using explanations which are not too technical, assumptive, simplistic, or demeaning. This responsibility falls to the relevant clinician. As managers are obliged to understand the difficulties of providing a clinical service, it is inappropriate for clinicians to cease communication with them, even when previous discussions have gone awry. Each issue must form the basis of a new initiative aimed at succeeding where others have failed.

Many managers are on relatively short term contracts which can be extended if performance targets are reached. They rarely have the luxury of the open ended contract currently applied to most consultants. Short term contracts may encourage expedient decisions which conflict with long term clinical needs. Pressures associated with a short term contract may undermine the manager's confidence and ability to perform. Although only some managers admit to it, their self esteem may also suffer because clinicians tend to command greater public respect. If this is not immediately apparent, I would ask you to consider how frequently the news media focus on advances in clinical care as the basis of good news, and how rarely they and the public praise the efforts of health managers as opposed to clinicians. Put yourself in the manager's place!

\section{What type of manager are you dealing with?}

In my experience, there is no stereotypical manager any more than there is a stereotypical clinician. It is essential that you try to get to know your managers, their strengths and their weaknesses. Much information can be obtained directly or indirectly from the comments of other consultants. Reputations abound concerning all members of hospital staff and it is worth listening to these selectively, preferably after drawing your own conclusions during the first few weeks in post. I have seen several newly appointed colleagues develop similar problems to my own after the initial period of euphoria which always accompanies a consultant appointment. However, I have greater respect for colleagues who listen to warnings but draw their own conclusions.

Certain criteria should be considered in relation to any manager. These include honesty, trustworthiness, competency, subservience or aggression, desire for personal gain, communication skills, and whether the manager is pragmatic or an abstract thinker.

Honesty can only be deduced from knowledge of the person concerned. It is my sad experience that some managers lie blatantly and without apology. I have seen this happen in front of national news media despite incontrovertible written evidence which confirmed that the manager's comments had no basis in truth. For some years as a consultant I was naive enough to believe that such a thing could never happen since our own profession places utmost importance on the integrity of medical practitioners and expects them at all times to be truthful, whether they are 
dealing with clinical work, research, or legal matters (such as reports or claim forms). In recent times, the term "flexibility" has been linked to the word truth, but to lie is to deliberately deceive. Although I consider it inexcusable, it may occur because the manager is fighting for personal survival. I have unfortunately seen this on several occasions and newly appointed consultants should be aware of such a possibility when managers are pushed to the limit. More commonly, managers are inadvertently untruthful and this usually occurs because they have misunderstood, or been misinformed, and therefore genuinely believe that they are stating the truth.

In my own mind, honesty refers to facts whilst trustworthiness pertains more to the reliability of the manager concerned. Only experience and feedback from colleagues allow trustworthiness and competency to be assessed.

Managerial subservience or aggression may confuse the clinician. An apparently subservient manager may be quiet but perceptive and speak with objectivity and astuteness when called upon. Such a manager may command a far greater respect than initially appears to be the case. Conversely, a more aggressive manager may appear to be an achiever and know all the answers but this may not prove to be the case since we all become weary of colleagues who can only present their case in an aggressive way.

Alliances at work in a social setting can easily bias personal attitudes and sometimes the apparently attentive ear belongs to a manager who has a greater affinity with someone who opposes the interests of the accident and emergency service. Many groups within our society have restricted membership and while you should not have to join to advance your cause, you must be aware of links between individuals who may compromise your arguments for their personal gain.

The relationship between consultants and managers often breaks down because of poor communication. With the increasing workload that is placed on all of usincluding managers-one has to work hard to try and stay abreast of developments and ensure if possible that time is reserved for brief but regular meetings with in-line managers. The accuracy of the information provided may have been distorted as it passes through the management chain and it is very helpful if the manager concerned has insight to know whether the information is accurate, probably accurate, or wishful thinking.

Finally, we can all be impressed by colleagues with a flair for abstract or lateral thinking but this may prove to be a distraction if there is no substance to it. The pragmatist may appear to lack charisma but can often achieve more than the apparently inspired manager who ends up in a blind alley.

\section{Which manager?}

In hospitals, one does not always have to relate to the first person in the management chain. It is important that newly appointed consultants obtain a chart explaining their local management structure and responsibilities so that they know who to approach on specific issues. Quite important $A \& E$ issues often have no allocated manager, and opportunities may be taken to sound out a number of managers before the problem is delegated. Sometimes this exercise is advantageous because a manager who is interested in the subject will agree to take it on. If you are in a situation in which you can approach more than one manager, I would suggest that you ask yourself the following questions: Which manager is in the know? Has most influence, particularly in the area concerned? Is most admired or feared? Achieves? Now has to bid for the necessary resources or generate appropriate funds?

\section{Motivating the manager}

Any approach to management on an important $A \& E$ issue may receive a lukewarm reception. In this situation, it is important that the consultant knows what drives the manager and the following are examples:

- charter standards

- quality standards

- audit findings

- good publicity

- support from the public

Charter standards appear to be written in stone and they generate pressure on managers from the Minister of Health downwards. Quality standards may originate from a number of sources including clinical, professional (for example, the Royal Colleges) and purchasing authorities. Clinical audit has provided an excellent opportunity for us to influence polices affecting $A \& E$ matters, either by demonstrating how quality can be improved or by showing where economies might be made. In my experience, managers thrive on good publicity, particularly if it involves the local press. If support for the A\&E service can be generated among the public, their servants, or local charities (for example, the Community Health Council, local officers of the British Heart Foundation, non-executive Trust Directors, even MPs) this can strengthen one's hand.

\section{"Ten Commandments"}

In trying to formulate advice for aspiring consultants in A\&E medicine who will soon be working with NHS managers, I have compiled a list of 10 points which I hope will be helpful. This is not an exhaustive list and colleagues will no doubt be able to improve on it.

(1) Try to be politically mature, patient, and pragmatickeep emotions to yourself.

(2) Explain your problem clearly and succinctlymanagers are frequently ignorant of $A \& E$ matters.

(3) Obtain the support of consultant colleagues (but sometimes managers will be more supportive).

(4) Protect yourself-retain copies of letters, important documents, and national as well as local guidelines.

(5) Find out how to pressurise managers to respond to certain issues. Consider approaching senior consultants, non-executive directors, the Community Health Council, charities, local fund raising organisations, and as a last resort, Members of Parliament.

(6) Do not say you are too busy to see managers or attend meetings - they are busy too and you will lose out from the breakdown of communication.

(7) If your proposals contain an element of personal gain, this will be detected and you will lose support.

(8) A team approach achieving benefit for everyone involved (including patients) stands the best chance of success.

(9) Do not accept denigration-a justified and well considered stance maintained in the face of hostility will earn you respect.

(10) Beware!-management will be thrust upon us all in time! We will be working with managers for the remainder of our careers and symbiosis must be the aim if we are all to benefit. As an $A \& E$ trainee, I received no specific guidance on this subject and I hope therefore that some of my comments will be of help.

A H SWAIN 